\title{
Chapter 8 \\ Whole Organisms or Pure Compounds? Entourage Effect Versus Drug Specificity
}

\author{
Sidarta Ribeiro
}

\begin{abstract}
As the therapeutic use of sacred plants and fungi becomes increasingly accepted by Western medicine, a tug of war has been taking place between those who advocate the traditional consumption of whole organisms and those who defend exclusively the utilization of purified compounds. The attempt to reduce organisms to single active principles is challenged by the sheer complexity of traditional medicine. Ayahuasca, for example, is a concoction of at least two plant species containing multiple psychoactive substances with complex interactions. Similarly, cannabis contains dozens of psychoactive substances whose specific combinations in different strains correspond to different types of therapeutic and cognitive effects. The "entourage effect" refers to the synergistic effects of the multiple compounds present in whole organisms, which may potentiate clinical efficacy while attenuating side effects. In opposition to this view, mainstream pharmacology is adamant about the need to use purified substances, presumably more specific and safe. In this chapter, I will review the evidence on both sides to discuss the scientific, economic, and political implications of this controversy. The evidence indicates that it is time to embrace the therapeutic complexity of psychedelics.
\end{abstract}

As Western medicine discovers the medicinal properties of whole organisms deemed sacred by traditional cultures, a fierce debate has been set between proponents of the use of purified chemicals versus supporters of long-established ritual uses of plants, fungi, and animals. As a professional neuroscientist with an interest in psychedelic medicines, it is clear to me that the attempt to reduce organisms to single active principles is challenged by the sheer complexity of traditional medicine. Ayahuasca, for example, is a concoction of at least two plant species containing multiple psychoactive substances with a plethora of interactions (Dos Santos et al., 2012; Mckenna, Towers, \& Abbott, 1984). Similarly, cannabis contains dozens of psychoactive substances whose specific combinations in different strains correspond to

\footnotetext{
S. Ribeiro $(\square)$

Brain Institute, Federal University of Rio Grande do Norte, Natal, RN, Brazil

e-mail: sidartaribeiro@neuro.ufrn.br 
distinct types of therapeutic and cognitive effects (Mechoulam, Hanus, Pertwee, \& Howlett, 2014). Is there a scientific basis for believing that single molecules are more useful for medicinal purposes than mixtures?

\section{Pharmacopeia of a Single Plant: The Case of Cannabis}

Much as the hundreds of dog breeds coevolved with humans in a genetic race for the satisfaction of quite specific human needs (Kekecs et al., 2016; Parker et al., 2017), cannabis coevolved with humans so as to satisfy a wide variety of therapeutic, recreational, and religious needs (Guy, Whittle, \& Robson, 2004; Pollan, 2001). There are over 700 strains of cannabis (Gloss, 2015; Sawler et al., 2015), each with characteristic concentrations of hundreds of substances of therapeutic interest, such as cannabinoids, terpenes, and phenols (Andre, Hausman, \& Guerriero, 2016; Formukong, Evans, \& Evans, 1988; Gertsch, Pertwee, \& Di Marzo, 2010). Dozens of cannabinoids have medicinal properties (Izzo, Borrelli, Capasso, Di Marzo, \& Mechoulam, 2009; Radwan et al., 2008). Tetrahydrocannabinol (THC), until recently the most studied cannabinoid of cannabis, possesses enormous therapeutic potential, with preliminary or advanced empirical evidence regarding a wide range of diseases, such as multiple sclerosis (Rekand, 2014; Zettl, Rommer, Hipp, \& Patejdl, 2016), ischemia (Zani, Braida, Capurro, \& Sala, 2007), Alzheimer's disease (Aso, Sanchez-Pla, Vegas-Lozano, Maldonado, \& Ferrer, 2015; Cao et al., 2014; Yu et al., 2016), lateral amyotrophic sclerosis (Weber, Goldman, \& Truniger, 2010), anorexia (Lewis \& Brett, 2010; Verty et al., 2011), Parkinson's disease (van Vliet, Vanwersch, Jongsma, Olivier, \& Philippens, 2008), diabetes (Gallant, Odei-Addo, Frost, \& Levendal, 2009), cystic fibrosis (Bregman \& Fride, 2011), chronic and neuropathic pain (Cannabis-based Medicines, 2003; Johnson et al., 2010; Johnson, Lossignol, Burnell-Nugent, \& Fallon, 2013), and epilepsy (Maccarrone, Maldonado, Casas, Henze, \& Centonze, 2017). Another very promising recent advance occurred in cancer; we now know that cannabinoids are useful in onco-therapy, not only to alleviate anxiety, pain, lack of appetite, and sleep due to chemotherapy or radiotherapy (Abrams, 2016) but also for their potent antitumor properties (Guzman, 2003; Huff \& Chan, 2000; Ladin, Soliman, Griffin, \& Van Dross, 2016; Lombard, Nagarkatti, \& Nagarkatti, 2005).

A major recent breakthrough revealed THC as a contender for holding the biggest promise of cognitive restoration for the aging human population. The study showed that chronic THC treatment reverses cognitive decline in older mice, restoring learning ability to the levels of young animals (Bilkei-Gorzo et al., 2017). THC treatment also restored synaptic plasticity to the levels typical of young animals, with a concomitant rescue of plasticity-related mRNA and protein levels and increase in the density of dendritic spines (Bilkei-Gorzo et al., 2017). The study showed further that adolescent mice are cognitively impaired after the same treatment, due to excessive plasticity. While it becomes increasingly clear why the early and excessive 
use of cannabis is ill-advised (Farnsworth, 1976; Schmits \& Quertemont, 2013), cannabis strives to supplant the cane as the elder's best friend.

Part of the resistance to cannabis as medicine relates to its great potential to replace or substantially change current therapies. Patients with epilepsy, Parkinson's disease, neuropathic pains, and several other illnesses treatable by cannabis are often refractory to medications presently available for medical prescription (Ohtsuka, Yoshinaga, \& Kobayashi, 2000). This problem is clinically addressed by increasing medication doses, leading to higher risks of side effects, which may include cardiac or respiratory arrest (Hookana et al., 2016). In contrast, cannabinoid medications are very safe to use, since there are no cannabinoid receptors in neurovegetative centers (Hu \& Mackie, 2015; Moldrich \& Wenger, 2000; Tsou, Brown, Sanudo-Pena, Mackie, \& Walker, 1998).

The main psychological deficit acutely caused by cannabis intake is an impairment of working memory (Fadda, Robinson, Fratta, Pertwee, \& Riedel, 2004). Interestingly, the scientific basis for the use of cannabis to treat a variety of diseases related to excess or inadequate neuronal synchronization, such as epilepsy, Parkinson's disease, Tourette syndrome, and chronic and neuropathic pain, is probably related to the same biological property that impairs working memory in a dose-dependent manner: the capacity of cannabinoids to desynchronize neuronal activity (Robbe et al., 2006). Working memory impairment is mostly related to THC and can be avoided by mixing it with other cannabinoids and terpenes (Cannabisbased medicines, 2003; Johnson et al., 2013; Koehler, 2014; Maccarrone et al., 2017; Patti, 2016; Rekand, 2014; Sastre-Garriga, Vila, Clissold, \& Montalban, 2011; Zettl et al., 2016), as typically for in natura cannabis (Russo, 2011). The antidepressant effects of cannabis (de Mello Schier et al., 2014; Jiang et al., 2005), as well as its use to mitigate the consequences of stroke (Bravo-Ferrer et al., 2017), are likely related to its role in the induction of neurogenesis (Avraham et al., 2014; Jin et al., 2004; Xapelli et al., 2013).

\section{Plants United, Entourage of Molecules}

The understanding of the medicinal use of whole organisms is greatly illuminated by the notion of entourage effect, a term coined by chemists Raphael Mechoulam and Simon Ben-Shabat to refer to the cooperative effects of the multiple compounds present in whole organisms that may potentiate clinical efficacy while attenuating side effects (Ben-Shabat et al., 1998). One clear example of such entourage effect is the additive effect of cannabidiol (CBD) and THC, two main constituents of cannabis, in the enhancement of radiotherapy for the treatment of glioma (Scott, Dalgleish, \& Liu, 2014). Cooperative effects also link cannabinoids to the perfumed organic compounds called terpenes. Chemically similar to cannabinoids and abundant in cannabis, these substances can facilitate the passage of chemicals through the blood-brain barrier and counterbalance memory deficits induced by THC (Russo, 2011). 
From the psychiatric point of view, CBD and THC have very different and, in fact, complementary effects (Fadda et al., 2004; Morgan, Freeman, Schafer, \& Curran, 2010; Morgan, Schafer, Freeman, \& Curran, 2010), with relaxation and sedation following CBD intake and excitation following THC intake. CBD is anxiolytic and antipsychotic, while THC is anxiogenic and pro-psychotic (Fakhoury, 2016; Sherif, Radhakrishnan, D’Souza, \& Ranganathan, 2016; Zuardi et al., 2012). In isolation and at high doses, these substances may have negative health effects, especially for people in key populations (Di Forti et al., 2009). On the other hand, the presence of both compounds in cannabis results in a buffered effect that is anything but unsafe from the patient's perspective (Silva, Balbino, \& Weiber, 2015).

\section{Did Science Finally Catch Up with the Traditional Shamans?}

Is cannabis beneficial? Is cannabis dangerous? Should we legalize cannabis? The absurdity of these questions can be exposed by performing an apt substitution: Are dogs beneficial? Are dogs dangerous? Should we legalize dogs? We must not forget that the traditional use of whole organisms such as cannabis coevolved with the plant itself (McPartland \& Guy, 2004; Pollan, 2001). Cannabis was probably used in the first rope, cloth, paper, and medicine. The Ebers Papyrus of Ancient Egypt ( $\sim 1550$ BC) contains a prescription of cannabis for inflammation (Dawson, 1934). We now know that the plant contains several anti-inflammatory substances (de Lago, Moreno-Martet, Cabranes, Ramos, \& Fernandez-Ruiz, 2012; Fabisiak \& Fichna, 2017; Liu, Fowler, \& Dalgleish, 2010; Molina-Holgado et al., 2003; Nagarkatti, Pandey, Rieder, Hegde, \& Nagarkatti, 2009; Zurier, 2003). The "Siberian Ice Lady," a beautifully tattooed mummy from the fifth century BC, discovered in 1993 in the Russian Altai Mountains near the borders of China, Mongolia, and Kazakhstan, was found with a pouch of cannabis at the rich burial site. The mummy also had a primary tumor in her right breast, with signs of metastasis (Letyagin, Savelov, \& Polosmak, 2014). Could the "Siberian Ice Lady" have used cannabis to treat cancer? In the past 17 years, biomedical research has shown that cannabinoids have antitumoral effects in breast cancer and a variety of other cancer types, including glioma, lung, colon, liver, skin, prostate, thyroid, and pancreatic cancer (Ladin et al., 2016).

The artificial selection of cannabis, performed widely in central Asia in the past 6000 years both north and south of the Himalayas, led to strains characterized by cannabinoid mixtures, rather than strains dominated by a single cannabinoid (Elsohly \& Slade, 2005; Fetterman \& Turner, 1972). We know now that an extract of the entire plant, with similar amounts of THC and CBD ("Sativex"), is more effective in reducing pain and spasms of multiple sclerosis than the pure synthetic compound, Dronabinol ("Marinol”), analogous to THC (Keating, 2017). If purified compounds were indeed always best for therapy, single-compound strains should have been favored over time. Yet, the opposite happens to be true. Traditional 
shamans use whole plants and have advocated for this sort of medicine as a major root of their practice (Labate \& Cavnar, 2014a). We should listen to our ancestors here.

\section{“Purified Compounds Only" Is Snake Oil}

What is best for medicinal use, whole organisms or isolated active principles? Mainstream pharmacology is adamant about the need to use purified substances for medical treatment, because these are presumably more specific and safe (Zuardi, Crippa, \& Hallak, 2010). This position is defended fiercely in the media and also in academic publications, as if there was much more clinical knowledge accumulated about the effects of the purified compounds than about the effects of whole organisms; however, this is often not the case. The traditional use of whole organisms has centuries and, in some cases, millennia of cultural experience, while purified compounds only recently started to be investigated. As a useful analogy, consider that to say that the use of purified cannabinoids is medically safer than the use of cannabis in natura is similar to the fallacy of considering cesarean delivery scientifically superior to natural childbirth. Rimonabant, an anti-obesity medicine based on an antagonist of a cannabinoid receptor, is the most infamous example of the potential dangers of a single compound; it was removed from the market in 2008 due to the association with suicide cases (Rimonabant, 2009; Topol et al., 2010). The whole cannabis plant, however, with various proportions of THC, CBD, and many other cannabinoids, is clinically safe for people outside key populations and can even be used in these populations provided that adequate, specific strains of cannabis are used. For example, CBD-rich cannabis is safe for psychotic patients and can be used as psychiatric treatment (Zuardi et al., 2012). In the case of ayahuasca, compound combination is advantageous not because of safety issues but due to the fact that the N-N-dimethyltryptamine (DMT) contained in the plant Psychotria viridis is entirely degraded by the monoamine oxidases (MAO) present in the gastrointestinal tract in the absence of pharmacological protection (Buckholtz \& Boggan, 1977). Indeed, the DMT contained in ayahuasca would be innocuous if the brew did not include another plant, the liana Banisteriopsis caapi, which is rich in inhibitors of MAO and therefore allows the psychedelic experience to occur. These substances by themselves increase the levels of dopamine and other neurotransmitters (Iurlo et al., 2001) and induce the formation of new neurons (Dakic et al., 2016). An argument favoring isolated compounds can perhaps be made for the use of psilocybin rather than whole mushrooms, although there is no symbolic equivalency between these forms of use; the rich cultural context of mushroom consumption comprises an important part of the setting that is absent in the case of ingesting a purified compound.

One cornerstone of the mesmerizing argument favoring purified compounds is the notion that their biological action is equally "pure" and, therefore, "specific," two very loaded words. Much of the credibility that psychiatrists have in the public debate, whether it is about the pharmacological treatment of mental illness or about 
drug policy, stems from the well-publicized specificity of the single compounds sold as psychiatric drugs. It may be surprising to most readers that the opposite happens to be true: Single molecules often bind to multiple receptors in the brain (Rickli, Moning, Hoener, \& Liechti, 2016; U'Prichard, 1980), at various dose-dependent affinities (Hamblin, Leff, \& Creese, 1984) and with complex long-distance (allosteric) molecular interactions (Price et al., 2005; Solt, Ruesch, Forman, Davies, \& Raines, 2007). The simple is simply not simple.

\section{Time to Debunk the Prohibition Myths}

Facing the inquisition, Galileo Galilei was forced, in 1663, to deny the notion that it is the Earth that moves around the Sun, not the other way around. Galileo is said to have muttered Eppur si muove ("And yet it moves") in an act of resistance to ecclesiastical irrationalism. This dire situation has parallels today in the deadlock in the public debate regarding the medical use of cannabinoid and serotonergic psychedelics.

The risks associated with these substances - in particular, cannabis and THC - have been used as an intellectual "straw man" in the public debate. Many of the substances sold in pharmacy are acutely dangerous at high doses, which is not the case with cannabis. To justify the prohibition of cannabis based on the existence of key populations at risk for cannabis use is to ignore that every substance has risks. To give a familiar example, it is not because there are people intolerant to lactose that milk should be banned. The way to deal with lactose intolerance is to inform consumers properly and to market lactose-free milk.

The prohibition paradigm feeds from a great degree of media-induced moral panic targeting specific illicit drugs (Forsyth, 2001), in disagreement with the scientific evidence regarding harm potential (Nutt, King, Phillips, \& Independent Scientific Committee on Drugs, 2010). The fallacious arguments used to bar whole organisms from the repertoire of official medical treatment often take the form of inadequate biological analogies, such as: "The purified compounds of snake venom are medicinal, but as a whole snake venom kills." This proposition does not survive inspection. The first drug derived from snake venom was an inhibitor of the angiotensin-converting enzyme, a toxin found in the venom of the Brazilian pit viper Bothrops jararaca (Ferreira, 1965; Rocha e Silva, 1963), and basis of synthetic compounds used worldwide to control high blood pressure, treat chronic heart failure, and prevent cardiovascular risk (Flather et al., 2000). Later snake-derived drugs include a modified version of an antiplatelet toxin produced by the rattlesnake Sistrurus miliarius barbouri, used broadly to treat heart attacks and prevent blood clotting (Phillips \& Scarborough, 1997). Both kinds of drugs are dangerous at high doses (Attaya, Kanthi, Aster, \& McCrae, 2009; Augenstein, Kulig, \& Rumack, 1988; Coons, Barcelona, Freedy, \& Hagerty, 2005; Dawson et al., 1990; Parakh, Naik, Rohatgi, Bhat, \& Parakh, 2009; Park, Purnell, \& Mirchandani, 1990), so it is disingenuous to sustain that whole venoms are lethal but purified compounds are not. 
The real motivation underlying the venom fallacy is the conflict of interest of the medical establishment, in bed with Big Pharma. Where will the profits come from, when medicine can be grown at home and used in small, infrequent doses? And yet, how will it be possible to block patients from accessing the life-transforming psychedelic medicine at very low cost?

The healthcare regulation of traditional medicine based on whole organisms must consider regional differences and social inequality. Currently, the illicit drug market is conducted through retail locations in poor neighborhoods and communities. Regulation in the context of legalization must be oriented to mitigate regional imbalances, to encourage harm reduction, and to promote the social inclusion of those who now live from the illicit market but are usually excluded from the debate on their regulation. Whole organisms offer hope in the treatment of substance abuse (Winkelman, 2014), as documented preliminarily for the use of cannabis to treat crack addiction (Labigalini Jr, Rodrigues, \& Da Silveira, 1999) and for the use of ayahuasca to treat alcohol, tobacco, and cocaine abuse (2014; Thomas, Lucas, Capler, Tupper, \& Martin, 2013).

\section{And Yet It Moves: The Psychedelic Renaissance Is On}

The year 2017 will be remembered as a landmark of the "psychedelic renaissance"; the terrible barriers that have been imposed for decades on the research and the therapeutic use of psychedelic substances-cannabis, ayahuasca, LSD, psilocybin, MDMA, DMT, and many others — are being lifted. In April, researchers from around the world gathered in Oakland for 3 days of intense exchange of knowledge at Psychedelic Science 2017, a meeting promoted by the Multidisciplinary Association for Psychedelic Studies (MAPS) and the Beckley Foundation. The first time I attended a MAPS congress, it was its 25th anniversary conference, the Cartographie Psychedelica in 2011. The bulk of the audience seemed composed of characters from J. R. Tolkien's The Lord of the Rings. The California hippie-chic mixed with few but quite serious scientists in an atmosphere of celebration of the interest of science in psychedelia. The congress attracted about 1100 people, and most of the interest seemed to fall on pure compounds of medicinal interest, although ayahuasca had its own track.

The following MAPS congress I attended, Psychedelic Science 2013, had about 2000 people and a noticeable change in composition. Scientists invaded Tolkien's arena, merging with the mythological beings of Middle-Earth in equal proportions. Anthropologist Beatriz Labate organized a crowded track of presentations on ayahuasca, marking the heightened public interest regarding traditional medicines that bring with them as complex cultural package, with a use setting of its own (Labate \& Cavnar, 2013, 2014a, 2014b).

Psychedelic Science 2017 grew like a tsunami. There were over 3000 participants, lots of renowned scientists, multiple events of scientific and artistic relevance, international press, and closed hotel rooms for documentary recording. The beings of Tolkien practically disappeared, although some still were present, undercover in 
plain clothes. The main difference of the 2017 congress compared to previous ones was the conspicuous arrival of foundations and companies interested in funding research on the use of psychedelics to treat anxiety, depression, post-traumatic stress syndrome, and even cancer. Importantly, the ayahuasca session grew into an entire track ("Plant Medicine") dedicated to whole organisms in general.

The meeting was remarkable for bringing up and coming mainstream, traditional, and syncretic contemporary medicine, together with hardcore science performed by leading researchers in cell and molecular biology, biochemistry, neurophysiology, psychology, and psychiatry. Thomas Insel, the 14-year director of the National Institute of Mental Health (NIMH), who resigned in 2015 to join Verily Life Sciences (Google's spin-off) and now heads the neuroscience company "Mindstrong", publicly acknowledged the immense therapeutic potential of psychedelics. Major advances in basic psychedelic research were presented. For instance, pharmacologist David Nichols, from Chapel Hill University, reported groundbreaking results on lysergic acid diethylamide (LSD), featured on Cell's cover, demonstrating that the molecular structure of the serotonin receptor locks LSD in its binding site (Wacker et al., 2017). In principle, this mechanism explains the delayed, and yet intense, long-lasting effects of LSD, even at tiny doses. This likely relates to the trendy habit of microdosing LSD, by which people seek cognitive and emotional enhancement without unintended side effects. Microdosing (including the use of whole plants or concoctions with low concentrations of psychedelic compounds) should be understood vis-à-vis the fact that most drug effects correlate with dose according to inverted-U curves, and therefore the use of low doses keeps effects on the rising side of the dose-response curve.

Also remarkable were the experimental results shown by molecular and cell biologist Stevens Rehen, from the D'Or Institute for Research and Teaching and Federal University of Rio de Janeiro, who showed that 5-methoxy-N,N-dimethyltryptamine (5-MeO-DMT), a psychedelic substance present in ayahuasca, in the indigenous snuff Yopo, and in the Sonoran desert toad Bufo alvarius (Barceloux, 2012), can induce neurogenesis (Dakic et al., 2016) and synaptic plasticity (Dakic et al., 2017).

Major advances in translational psychedelic research were also featured. The research presented by neuroscientist Draulio de Araujo was one of the biggest highlights. With his team from the Federal University of Rio Grande do Norte, Araujo obtained excellent evidence that ayahuasca is quite useful in the effective care of treatment-resistant major depression in a randomized, placebo-controlled clinical trial (Palhano-Fontes et al., 2017). In contrast with regular antidepressants that take weeks to act, ayahuasca quickly attenuates depressive symptoms (Osorio et al., 2015), with a significant effect 40 min after ingestion (Sanches et al., 2016). Importantly, when compared to placebo, this effect persists for at least 7 days (Palhano-Fontes et al., 2017), substantially more than the effect obtained with the single-molecule ketamine, at present ayahuasca's direct clinical competitor for fast yet durable antidepressant effect (Romeo, Choucha, Fossati, \& Rotge, 2015; Zarate Jr et al., 2006). Preliminary results from the Araujo group indicate that the antidepressant effect is proportional to the degree of perceptual alteration (Palhano-Fontes, 2017), which is known to involve major activation of visual cortical areas (de Araujo 
et al., 2012). In the author's own words, "the more intense the psychedelic experience, the stronger is the antidepressant effect" (Palhano-Fontes, 2017).

\section{Prohibition: What Is to Be Done?}

The core issue at stake is the fact that the phyto-therapeutic approach to psychedelic medicine is successful in multiple countries, and quite scalable, due to the low cost of home-growing whole organisms. The therapeutic use of cannabis is currently legal in Austria, Belgium, Canada, Chile, Colombia, the Czech Republic, Finland, Israel, the Netherlands, Spain, the United Kingdom, Uruguay and several US states. Ayahuasca is currently legal in multiple countries (Labate \& Cavnar, 2014a, 2014b).

Phyto-therapeutic medicine is feasible because doses can be kept within controlled ranges and because knowing the precise dose is often not essential for effective therapeutics. After all, few would defend the notion that taking vitamin pills provides better nutrition than eating fresh fruit and vegetables. Purified compounds are much more expensive to make and necessarily reach the final consumer at much higher prices than whole organisms. The clinical use of purified compounds for subjects with low socioeconomic status is further hampered by Big Pharma patent rights and marketing strategies. Still, in recent years, the large margin of profit for the commercialization of purified compounds has motivated a strong corporative push for the adoption of purified compounds as the gold standard for medical practice involving psychedelic substances. In the case of medical marijuana, cannabis in natura versus isolated cannabinoids is a billion-dollar question.

To make safe use of any substance, it is necessary to understand its use in three different dimensions of the experience: substance (dose, interaction), set (body and mind), and setting (social context). Prohibition compromises the three dimensions altogether. With regard to the substance, it increases the chances of dose uncertainty, contamination, and degradation. With respect to the set, it hinders free dialogue about key populations. With regard to the setting, it promotes violence, paranoia, marginalization, and stigmatization. Prohibition is the heaviest of all drugs, and the ban on psychedelic drugs leads to unregulated iatrogenic use without harm reduction, nor scientific control, decreasing the protection of the society.

In view of current scientific knowledge (Abrams, 2016; Ben Amar, 2006; Fasinu, Phillips, ElSohly, \& Walker, 2016; Ladin et al., 2016; Rosenberg, Tsien, Whalley, \& Devinsky, 2015; Sznitman \& Lewis, 2015), it is of paramount importance for medicine and research to legalize the use, possession, planting, cultivation, harvesting, manipulation, manufacture, distribution, marketing, import, export, and prescription of Cannabis sativa L. and other varieties of cannabis, as well as products obtained from these plants. The same applies to ayahuasca, peyote, mushrooms, toads, and various other psychedelic organisms (Labate \& Cavnar, 2014a, 2014b). Whole organisms must be legalized and regulated to protect people at risk and respect users. These measures will give doctors, patients, and researchers maximum therapeutic options and the widest range of tools while at the same time 
reducing costs, offering access options according to each patient profile or type of research, avoiding dependence on foreign products, and preventing patients from buying medicine from the illicit market of questionable quality and with active principles in unknown concentrations. These measures will also promote production by patient associations and promote the self-care of patients who carry out their own cultivation.

We are living in the era of psychedelic renaissance. Science finally caught up with the knowledge, wisdom, and curiosity of healers and psychonauts, and the new medicine of the future may come from ancient medicine invented by Amazonian pajés and Siberian shamans of the past. New questions are becoming as widespread as new answers. Now is the prime time to discuss the potential advantages and disadvantages of therapeutics based on whole organisms versus purified compounds, a debate with major economic, social, and philosophical implications for the future of human health.

\section{References}

Abrams, D. I. (2016). Integrating cannabis into clinical cancer care. Current Oncology, 23(2), S8-S14. https://doi.org/10.3747/co.23.3099

Andre, C. M., Hausman, J. F., \& Guerriero, G. (2016). Cannabis sativa: The plant of the thousand and one molecules. Frontiers in Plant Science, 7, 19. https://doi.org/10.3389/fpls.2016.00019

Aso, E., Sanchez-Pla, A., Vegas-Lozano, E., Maldonado, R., \& Ferrer, I. (2015). Cannabis-based medicine reduces multiple pathological processes in AbetaPP/PS1 mice. Journal of Alzheimer's Disease, 43(3), 977-991. https://doi.org/10.3233/JAD-141014

Attaya, S., Kanthi, Y., Aster, R., \& McCrae, K. (2009). Acute profound thrombocytopenia with second exposure to eptifibatide associated with a strong antibody reaction. Platelets, 20(1), 64-67. https://doi.org/10.1080/09537100802592676

Augenstein, W. L., Kulig, K. W., \& Rumack, B. H. (1988). Captopril overdose resulting in hypotension. JAMA, 259(22), 3302-3305.

Avraham, H. K., Jiang, S., Fu, Y., Rockenstein, E., Makriyannis, A., Zvonok, A., ... Avraham, S. (2014). The cannabinoid $\mathrm{CB}(2)$ receptor agonist AM1241 enhances neurogenesis in GFAP/ Gp120 transgenic mice displaying deficits in neurogenesis. British Journal of Pharmacology, 171(2), 468-479. https://doi.org/10.1111/bph.12478

Barceloux, D. G. (2012). Medical toxicology of drug abuse: Synthesized chemicals and psychoactive plants. Hoboken, $\mathrm{NJ}$ : Wiley.

Ben Amar, M. (2006). Cannabinoids in medicine: A review of their therapeutic potential. Journal of Ethnopharmacology, 105(1-2), 1-25. https://doi.org/10.1016/j.jep.2006.02.001

Ben-Shabat, S., Fride, E., Sheskin, T., Tamiri, T., Rhee, M. H., Vogel, Z., ... Mechoulam, R. (1998). An entourage effect: Inactive endogenous fatty acid glycerol esters enhance 2-arachidonoyl-glycerol cannabinoid activity. European Journal of Pharmacology, 353(1), 23-31.

Bilkei-Gorzo, A., Albayram, O., Draffehn, A., Michel, K., Piyanova, A., Oppenheimer, H., ... Zimmer, A. (2017). A chronic low dose of Delta9-tetrahydrocannabinol (THC) restores cognitive function in old mice. Nature Medicine, 23(6), 782-787. https://doi.org/10.1038/nm.4311

Bravo-Ferrer, I., Cuartero, M. I., Zarruk, J. G., Pradillo, J. M., Hurtado, O., Romera, V. G., ... Moro, M. A. (2017). Cannabinoid type-2 receptor drives neurogenesis and improves functional outcome after stroke. Stroke, 48(1), 204-212. https://doi.org/10.1161/STROKEAHA.116. 014793 
Bregman, T., \& Fride, E. (2011). Treatment with tetrahydrocannabinol (THC) prevents infertility in male cystic fibrosis mice. Journal of Basic and Clinical Physiology and Pharmacology, 22 (1-2), 29-32. https://doi.org/10.1515/jbcpp.2011.004

Buckholtz, N. S., \& Boggan, W. O. (1977). Monoamine oxidase inhibition in brain and liver produced by beta-carbolines: Structure-activity relationships and substrate specificity. Biochemical Pharmacology, 26(21), 1991-1996.

Cannabis-based medicines--GW pharmaceuticals: High CBD, high THC, medicinal cannabis--GW pharmaceuticals, THC:CBD. (2003). Drugs R D, 4(5), 306-309.

Cao, C., Li, Y., Liu, H., Bai, G., Mayl, J., Lin, X., . . Cai, J. (2014). The potential therapeutic effects of THC on Alzheimer's disease. Journal of Alzheimer's Disease, 42(3), 973-984. https:// doi.org/10.3233/JAD-140093

Coons, J. C., Barcelona, R. A., Freedy, T., \& Hagerty, M. F. (2005). Eptifibatide-associated acute, profound thrombocytopenia. Annals of Pharmacotherapy, 39(2), 368-372. https://doi.org/10. 1345/aph.1E244

Dakic, V., Maciel, R. M., Drummond, H., Nascimento, J. M., Trindade, P., \& Rehen, S. K. (2016). Harmine stimulates proliferation of human neural progenitors. PeerJ, 4, e2727. https://doi.org/ $10.7717 /$ peerj. 2727

Dakic, V., Nascimento, J. M., Sartore, R. C., Maciel, R. M., de Araujo, D. B., Ribeiro, S., ... Rehen, S. K. (2017). Short term changes in the proteome of human cerebral organoids induced by 5-methoxy-N,N-dimethyltryptamine. BioRxiv. https://doi.org/10.1101/108159

Dawson, W. (1934). Studies in the Egyptian medical texts: III. The Journal of Egyptian Archaeology, 20(1/2), 41-46.

Dawson, A. H., Harvey, D., Smith, A. J., Taylor, M., Whyte, I. M., Johnson, C. I., . . Roberts, M. J. (1990). Lisinopril overdose. Lancet, 335(8687), 487-488.

de Araujo, D. B., Ribeiro, S., Cecchi, G. A., Carvalho, F. M., Sanchez, T. A., Pinto, J. P., ... Santos, A. C. (2012). Seeing with the eyes shut: Neural basis of enhanced imagery following ayahuasca ingestion. Human Brain Mapping, 33(11), 2550-2560. https://doi.org/10.1002/ hbm. 21381

de Lago, E., Moreno-Martet, M., Cabranes, A., Ramos, J. A., \& Fernandez-Ruiz, J. (2012). Cannabinoids ameliorate disease progression in a model of multiple sclerosis in mice, acting preferentially through CB1 receptor-mediated anti-inflammatory effects. Neuropharmacology, 62(7), 2299-2308. https://doi.org/10.1016/j.neuropharm.2012.01.030

de Mello Schier, A. R., de Oliveira Ribeiro, N. P., Coutinho, D. S., Machado, S., Arias-Carrion, O., Crippa, J. A., ... Silva, A. C. (2014). Antidepressant-like and anxiolytic-like effects of cannabidiol: A chemical compound of Cannabis sativa. CNS \& Neurological Disorders-Drug Targets, 13(6), 953-960.

Di Forti, M., Morgan, C., Dazzan, P., Pariante, C., Mondelli, V., Marques, T. R., ... Murray, R. M. (2009). High-potency cannabis and the risk of psychosis. The British Journal of Psychiatry, 195 (6), 488-491. https://doi.org/10.1192/bjp.bp.109.064220

Dos Santos, R. G., Grasa, E., Valle, M., Ballester, M. R., Bouso, J. C., Nomdedeu, J. F., . . Riba, J. (2012). Pharmacology of ayahuasca administered in two repeated doses. Psychopharmacology (Berl), 219(4), 1039-1053. https://doi.org/10.1007/s00213-011-2434-x

Elsohly, M. A., \& Slade, D. (2005). Chemical constituents of marijuana: The complex mixture of natural cannabinoids. Life Sciences, 78(5), 539-548. https://doi.org/10.1016/j.lfs.2005.09.011

Fabisiak, A., \& Fichna, J. (2017). Cannabinoids as gastrointestinal anti-inflammatory drugs. Neurogastroenterology \& Motility, 29(3). https://doi.org/10.1111/nmo.13038

Fadda, P., Robinson, L., Fratta, W., Pertwee, R. G., \& Riedel, G. (2004). Differential effects of THC- or CBD-rich cannabis extracts on working memory in rats. Neuropharmacology, 47(8), 1170-1179. https://doi.org/10.1016/j.neuropharm.2004.08.009

Fakhoury, M. (2016). Could cannabidiol be used as an alternative to antipsychotics? Journal of Psychiatric Research, 80, 14-21. https://doi.org/10.1016/j.jpsychires.2016.05.013

Farnsworth, D. L. (1976). What is the evidence for an amotivational syndrome in cannabis users? Annals of the New York Academy of Sciences, 282(1), 1. 
Fasinu, P. S., Phillips, S., ElSohly, M. A., \& Walker, L. A. (2016). Current status and prospects for cannabidiol preparations as new therapeutic agents. Pharmacotherapy, 36(7), 781-796. https://doi.org/10.1002/phar.1780

Ferreira, S. H. (1965). A bradykinin-potentiating factor (bpf) present in the venom of bothrops jararaca. British Journal of Pharmacology and Chemotherapy, 24(1), 163-169. https://doi.org/ 10.1111/j.1476-5381.1965.tb02091.x

Fetterman, P. S., \& Turner, C. E. (1972). Constituents of Cannabis sativa L. I. Propyl homologs of cannabinoids from an Indian variant. Journal of Pharmaceutical Sciences, 61(9), 1476-1477.

Flather, M. D., Yusuf, S., Kober, L., Pfeffer, M., Hall, A., Murray, G., .. Braunwald, E. (2000). Long-term ACE-inhibitor therapy in patients with heart failure or left-ventricular dysfunction: A systematic overview of data from individual patients. ACE-Inhibitor Myocardial Infarction Collaborative Group. Lancet, 355(9215), 1575-1581.

Formukong, E. A., Evans, A. T., \& Evans, F. J. (1988). Analgesic and antiinflammatory activity of constituents of Cannabis sativa L. Inflammation, 12(4), 361-371.

Forsyth, A. J. M. (2001). Distorted? A quantitative exploration of drug fatality reports in the popular press. The International Journal of Drug Policy, 12(5-6), 435-453. https://doi.org/10.1016/ S0955-3959(01)00092-5

Gallant, M., Odei-Addo, F., Frost, C. L., \& Levendal, R. A. (2009). Biological effects of THC and a lipophilic cannabis extract on normal and insulin resistant 3T3-L1 adipocytes. Phytomedicine, 16(10), 942-949. https://doi.org/10.1016/j.phymed.2009.02.013

Gertsch, J., Pertwee, R. G., \& Di Marzo, V. (2010). Phytocannabinoids beyond the Cannabis plant - do they exist? British Journal of Pharmacology, 160(3), 523-529. https://doi.org/10. 1111/j.1476-5381.2010.00745.x

Gloss, D. (2015). An overview of products and bias in research. Neurotherapeutics, 12(4), 731-734. https://doi.org/10.1007/s13311-015-0370-x

Guy, G. W., Whittle, B. A., \& Robson, P. (2004). The medicinal uses of cannabis and cannabinoids. Chicago, IL: Pharmaceutical Press.

Guzman, M. (2003). Cannabinoids: Potential anticancer agents. Nature Reviews Cancer, 3(10), 745-755. https://doi.org/10.1038/nrc1188

Hamblin, M. W., Leff, S. E., \& Creese, I. (1984). Interactions of agonists with D-2 dopamine receptors: Evidence for a single receptor population existing in multiple agonist affinity-states in rat striatal membranes. Biochemical Pharmacology, 33(6), 877-887.

Hookana, E., Ansakorpi, H., Kortelainen, M. L., Junttila, M. J., Kaikkonen, K. S., Perkiomaki, J., \& Huikuri, H. V. (2016). Antiepileptic medications and the risk for sudden cardiac death caused by an acute coronary event: A prospective case-control study. Annals of Medicine, 48(1-2), 111-117. https://doi.org/10.3109/07853890.2016.1140225

Hu, S. S., \& Mackie, K. (2015). Distribution of the endocannabinoid system in the central nervous system. Handbook of Experimental Pharmacology, 231, 59-93. https://doi.org/10.1007/978-3319-20825-1_3

Huff, J., \& Chan, P. (2000). Antitumor effects of THC. Environmental Health Perspectives, 108 (10), A442-A443.

Iurlo, M., Leone, G., Schilstrom, B., Linner, L., Nomikos, G., Hertel, P., ... Svensson, H. (2001). Effects of harmine on dopamine output and metabolism in rat striatum: Role of monoamine oxidase-A inhibition. Psychopharmacology (Berl), 159(1), 98-104. https://doi.org/10.1007/ s002130100879

Izzo, A. A., Borrelli, F., Capasso, R., Di Marzo, V., \& Mechoulam, R. (2009). Non-psychotropic plant cannabinoids: New therapeutic opportunities from an ancient herb. Trends in Pharmacological Sciences, 30(10), 515-527. https://doi.org/10.1016/j.tips.2009.07.006

Jiang, W., Zhang, Y., Xiao, L., Van Cleemput, J., Ji, S. P., Bai, G., \& Zhang, X. (2005). Cannabinoids promote embryonic and adult hippocampus neurogenesis and produce anxiolyticand antidepressant-like effects. The Journal of Clinical Investigation, 115(11), 3104-3116. https://doi.org/10.1172/JCI25509 
Jin, K., Xie, L., Kim, S. H., Parmentier-Batteur, S., Sun, Y., Mao, X. O., . . Greenberg, D. (2004). Defective adult neurogenesis in CB1 cannabinoid receptor knockout mice. Molecular Pharmacology, 66(2), 204-208. https://doi.org/10.1124/mol.66.2.204

Johnson, J. R., Burnell-Nugent, M., Lossignol, D., Ganae-Motan, E. D., Potts, R., \& Fallon, M. T. (2010). Multicenter, double-blind, randomized, placebo-controlled, parallel-group study of the efficacy, safety, and tolerability of THC:CBD extract and THC extract in patients with intractable cancer-related pain. Journal of Pain and Symptom Management, 39(2), 167-179. https://doi.org/ 10.1016/j.jpainsymman.2009.06.008

Johnson, J. R., Lossignol, D., Burnell-Nugent, M., \& Fallon, M. T. (2013). An open-label extension study to investigate the long-term safety and tolerability of THC/CBD oromucosal spray and oromucosal THC spray in patients with terminal cancer-related pain refractory to strong opioid analgesics. Journal of Pain and Symptom Management, 46(2), 207-218. https://doi.org/10. 1016/j.jpainsymman.2012.07.014

Keating, G. M. (2017). Delta-9-Tetrahydrocannabinol/Cannabidiol oromucosal spray (Sativex(R)): A review in multiple sclerosis-related spasticity. Drugs, 77(5), 563-574. https://doi.org/10. 1007/s40265-017-0720-6

Kekecs, Z., Szollosi, A., Palfi, B., Szaszi, B., Kovacs, K. J., Dienes, Z., \& Aczel, B. (2016). Commentary: Oxytocin-gaze positive loop and the coevolution of human-dog bonds. Frontiers in Neuroscience, 10, 155. https://doi.org/10.3389/fnins.2016.00155

Koehler, J. (2014). Who benefits most from THC:CBD spray? Learning from clinical experience. European Neurology, 71(Suppl 1), 10-15. https://doi.org/10.1159/000357743

Labate, B. C., \& Cavnar, C. (2013). The therapeutic use of ayahuasca. New York, NY: Springer.

Labate, B. C., \& Cavnar, C. (2014a). Ayahuasca shamanism in the Amazon and beyond. New York, NY: Oxford University Press.

Labate, B. C., \& Cavnar, C. (2014b). Prohibition, religious freedom, and human rights: Regulating traditional drug use. New York, NY: Springer.

Labigalini, E., Jr., Rodrigues, L. R., \& Da Silveira, D. X. (1999). Therapeutic use of cannabis by crack addicts in Brazil. Journal of Psychoactive Drugs, 31(4), 451-455. https://doi.org/10.1080/ 02791072.1999.10471776

Ladin, D. A., Soliman, E., Griffin, L., \& Van Dross, R. (2016). Preclinical and clinical assessment of cannabinoids as anti-cancer agents. Frontiers in Pharmacology, 7, 361. https://doi.org/10. 3389/fphar.2016.00361

Letyagin, A. Y., Savelov, A. A., \& Polosmak, A. A. (2014). High field magnetic resonance imaging of a mummy from Ak-Alakha-3 mound 1, Ukok plateau, Gorny Altai: Findings and interpretations. Archaeology Ethnology \& Anthropology of Eurasia, 42(4), 83-91.

Lewis, D. Y., \& Brett, R. R. (2010). Activity-based anorexia in C57/BL6 mice: Effects of the phytocannabinoid, Delta9-tetrahydrocannabinol (THC) and the anandamide analogue, OMDM2. European Neuropsychopharmacology, 20(9), 622-631. https://doi.org/10.1016/j.euroneuro. 2010.04.002

Liu, W. M., Fowler, D. W., \& Dalgleish, A. G. (2010). Cannabis-derived substances in cancer therapy--an emerging anti-inflammatory role for the cannabinoids. Current Clinical Pharmacology, 5(4), 281-287.

Lombard, C., Nagarkatti, M., \& Nagarkatti, P. S. (2005). Targeting cannabinoid receptors to treat leukemia: Role of cross-talk between extrinsic and intrinsic pathways in Delta9tetrahydrocannabinol (THC)-induced apoptosis of Jurkat cells. Leukemia Research, 29(8), 915-922. https://doi.org/10.1016/j.leukres.2005.01.014

Maccarrone, M., Maldonado, R., Casas, M., Henze, T., \& Centonze, D. (2017). Cannabinoids therapeutic use: What is our current understanding following the introduction of THC, THC: CBD oromucosal spray and others? Expert Review of Clinical Pharmacology, 10(4), 443-455. https://doi.org/10.1080/17512433.2017.1292849

Mckenna, D. J., Towers, G. H. N., \& Abbott, F. (1984). Monoamine-oxidase inhibitors in SouthAmerican hallucinogenic plants: Tryptamine and beta-carboline constituents of ayahuasca. Journal of Ethnopharmacology, 10, 195-223. 
McPartland, J. M., \& Guy, G. W. (2004). The evolution of Cannabis and coevolution with the cannabinoid receptor-a hypothesis. In G. Guy, B. A. Whittle, \& P. Robson (Eds.), The medicinal use of cannabis and cannabinoids (pp. 71-101). Grayslake, IL: Pharmaceutical Press.

Mechoulam, R., Hanus, L. O., Pertwee, R., \& Howlett, A. C. (2014). Early phytocannabinoid chemistry to endocannabinoids and beyond. Nature Reviews Neuroscience, 15(11), 757-764. https://doi.org/10.1038/nrn3811

Moldrich, G., \& Wenger, T. (2000). Localization of the CB1 cannabinoid receptor in the rat brain. An immunohistochemical study. Peptides, 21(11), 1735-1742.

Molina-Holgado, F., Pinteaux, E., Moore, J. D., Molina-Holgado, E., Guaza, C., Gibson, R. M., \& Rothwell, N. J. (2003). Endogenous interleukin-1 receptor antagonist mediates antiinflammatory and neuroprotective actions of cannabinoids in neurons and glia. Journal of Neuroscience, 23(16), 6470-6474.

Morgan, C. J., Freeman, T. P., Schafer, G. L., \& Curran, H. V. (2010). Cannabidiol attenuates the appetitive effects of Delta 9-tetrahydrocannabinol in humans smoking their chosen cannabis. Neuropsychopharmacology, 35(9), 1879-1885. https://doi.org/10.1038/npp.2010.58

Morgan, C. J., Schafer, G., Freeman, T. P., \& Curran, H. V. (2010). Impact of cannabidiol on the acute memory and psychotomimetic effects of smoked cannabis: naturalistic study: Naturalistic study [corrected]. The British Journal of Psychiatry, 197(4), 285-290. https://doi.org/10.1192/ bjp.bp. 110.077503

Nagarkatti, P., Pandey, R., Rieder, S. A., Hegde, V. L., \& Nagarkatti, M. (2009). Cannabinoids as novel anti-inflammatory drugs. Future Medicinal Chemistry, 1(7), 1333-1349. https://doi.org/ 10.4155/fmc.09.93

Nutt, D. J., King, L. A., Phillips, L. D., \& Independent Scientific Committee on Drugs. (2010). Drug harms in the UK: A multicriteria decision analysis. Lancet, 376(9752), 1558-1565. https://doi. org/10.1016/S0140-6736(10)61462-6

Ohtsuka, Y., Yoshinaga, H., \& Kobayashi, K. (2000). Refractory childhood epilepsy and factors related to refractoriness. Epilepsia, 41(Suppl 9), 14-17.

Osorio, L., Sanches, R. F., Macedo, L. R., Santos, R. G., Maia-de-Oliveira, J. P., Wichert-Ana, L., ... Hallak, J. E. (2015). Antidepressant effects of a single dose of ayahuasca in patients with recurrent depression: A preliminary report. Revista Brasileira de Psiquiatria, 37(1), 13-20. https://doi.org/10.1590/1516-4446-2014-1496

Palhano-Fontes, F. (2017). Os efeitos antidepressivos da ayahuasca, suas bases neurais e relação com a experiência psicodélica [The antidepressant effects of ayahuasca, its neural bases and relation with the psychedelic experience] (Doctoral dissertation). Federal University of Rio Grande do Norte, Natal. Retrieved from https://repositorio.ufrn.br/jspui/handle/123456789/ 24156

Palhano-Fontes, F., Barreto, D., Onias, H., Andrade, K. C., Novaes, M., Pessoa, J., . . . de Araujo, D. B. (2017). Rapid antidepressant effects of the psychedelic ayahuasca in treatment-resistant depression: A randomised placebo-controlled trial. BioRxiv. https://doi.org/10.1101/103531

Parakh, S., Naik, N., Rohatgi, N., Bhat, U., \& Parakh, K. (2009). Eptifibatide overdose. International Journal of Cardiology, 131(3), 430-432. https://doi.org/10.1016/j.ijcard.2007.07.132

Park, H., Purnell, G. V., \& Mirchandani, H. G. (1990). Suicide by captopril overdose. Journal of Toxicology: Clinical Toxicology, 28(3), 379-382.

Parker, H. G., Dreger, D. L., Rimbault, M., Davis, B. W., Mullen, A. B., Carpintero-Ramirez, G., \& Ostrander, E. A. (2017). Genomic analyses reveal the influence of geographic origin, migration, and hybridization on modern dog breed development. Cell Reports, 19(4), 697-708. https://doi. org/10.1016/j.celrep.2017.03.079

Patti, F. (2016). Health authorities data collection of THC:CBD oromucosal spray (L'Agenzia Italiana del Farmaco Web Registry): Figures after 1.5 years. European Neurology, 75(Suppl 1), 9-12. https://doi.org/10.1159/000444236

Phillips, D. R., \& Scarborough, R. M. (1997). Clinical pharmacology of eptifibatide. American Journal of Cardiology, 80(4A), 11B-20B. 
Pollan, M. (2001). The botany of desire: A plant's eye view of the world (1st ed.). New York, NY: Random House.

Price, M. R., Baillie, G. L., Thomas, A., Stevenson, L. A., Easson, M., Goodwin, R., .. . Ross, R. A. (2005). Allosteric modulation of the cannabinoid CB1 receptor. Molecular Pharmacology, 68 (5), 1484-1495. https://doi.org/10.1124/mol.105.016162

Radwan, M. M., Elsohly, M. A., Slade, D., Ahmed, S. A., Wilson, L., El-Alfy, A. T., . . Ross, S. A. (2008). Non-cannabinoid constituents from a high potency Cannabis sativa variety. Phytochemistry, 69(14), 2627-2633. https://doi.org/10.1016/j.phytochem.2008.07.010

Rekand, T. (2014). THC:CBD spray and MS spasticity symptoms: Data from latest studies. European Neurology, 71(Suppl 1), 4-9. https://doi.org/10.1159/000357742

Rickli, A., Moning, O. D., Hoener, M. C., \& Liechti, M. E. (2016). Receptor interaction profiles of novel psychoactive tryptamines compared with classic hallucinogens. European Neuropsychopharmacology, 26(8), 1327-1337. https://doi.org/10.1016/j.euroneuro.2016.05. 001

Rimonabant: Depression and suicide. (2009). Prescrire International, 18(99), 24.

Robbe, D., Montgomery, S. M., Thome, A., Rueda-Orozco, P. E., McNaughton, B. L., \& Buzsaki, G. (2006). Cannabinoids reveal importance of spike timing coordination in hippocampal function. Nature Neuroscience, 9(12), 1526-1533. https://doi.org/10.1038/nn1801

Rocha e Silva, M. (1963). The physiological significance of bradykinin. Annals of the New York Academy of Sciences, 104, 190-210.

Romeo, B., Choucha, W., Fossati, P., \& Rotge, J. Y. (2015). Meta-analysis of short- and mid-term efficacy of ketamine in unipolar and bipolar depression. Psychiatry Research, 230(2), 682-688. https://doi.org/10.1016/j.psychres.2015.10.032

Rosenberg, E. C., Tsien, R. W., Whalley, B. J., \& Devinsky, O. (2015). Cannabinoids and epilepsy. Neurotherapeutics, 12(4), 747-768. https://doi.org/10.1007/s13311-015-0375-5

Russo, E. B. (2011). Taming THC: Potential cannabis synergy and phytocannabinoid-terpenoid entourage effects. British Journal of Pharmacology, 163(7), 1344-1364. https://doi.org/10. 1111/j.1476-5381.2011.01238.x

Sanches, R. F., de Lima Osorio, F., Dos Santos, R. G., Macedo, L. R., Maia-de-Oliveira, J. P., Wichert-Ana, L., . . Hallak, J. E. (2016). Antidepressant effects of a single dose of ayahuasca in patients with recurrent depression: A SPECT study. Journal of Clinical Psychopharmacology, 36(1), 77-81. https://doi.org/10.1097/JCP.0000000000000436

Sastre-Garriga, J., Vila, C., Clissold, S., \& Montalban, X. (2011). THC and CBD oromucosal spray (Sativex $(\mathrm{R}))$ in the management of spasticity associated with multiple sclerosis. Expert Review of Neurotherapeutics, 11(5), 627-637. https://doi.org/10.1586/ern.11.47

Sawler, J., Stout, J. M., Gardner, K. M., Hudson, D., Vidmar, J., Butler, L., . . Myles, S. (2015). The genetic structure of marijuana and hemp. PLoS One, 10(8), e0133292. https://doi.org/10. 1371/journal.pone.0133292

Schmits, E., \& Quertemont, E. (2013). Les drogues dites "douces": Cannibas et syndrome amotivationnel [So called "soft" drugs: cannabis and the amotivational syndrome]. Revue Médicale de Liège, 68(5-6), 281-286.

Scott, K. A., Dalgleish, A. G., \& Liu, W. M. (2014). The combination of cannabidiol and Delta9tetrahydrocannabinol enhances the anticancer effects of radiation in an orthotopic murine glioma model. Molecular Cancer Therapeutics, 13(12), 2955-2967. https://doi.org/10.1158/ 1535-7163.MCT-14-0402

Sherif, M., Radhakrishnan, R., D’Souza, D. C., \& Ranganathan, M. (2016). Human laboratory studies on Cannabinoids and psychosis. Biological Psychiatry, 79(7), 526-538. https://doi.org/ 10.1016/j.biopsych.2016.01.011

Silva, T. B., Balbino, C. Q., \& Weiber, A. F. (2015). The relationship between cannabidiol and psychosis: A review. Annals of Clinical Psychiatry, 27(2), 134-141.

Solt, K., Ruesch, D., Forman, S. A., Davies, P. A., \& Raines, D. E. (2007). Differential effects of serotonin and dopamine on human 5-HT3A receptor kinetics: Interpretation within an allosteric 
kinetic model. Journal of Neuroscience, 27(48), 13151-13160. https://doi.org/10.1523/ JNEUROSCI.3772-07.2007

Sznitman, S. R., \& Lewis, N. (2015). Is cannabis an illicit drug or a medicine? A quantitative framing analysis of Israeli newspaper coverage. International Journal of Drug Policy, 26(5), 446-452. https://doi.org/10.1016/j.drugpo.2015.01.010

Thomas, G., Lucas, P., Capler, N. R., Tupper, K. W., \& Martin, G. (2013). Ayahuasca-assisted therapy for addiction: Results from a preliminary observational study in Canada. Current Drug Abuse Reviews, 6(1), 30-42.

Topol, E. J., Bousser, M. G., Fox, K. A., Creager, M. A., Despres, J. P., Easton, J. D., ... Investigators, C. (2010). Rimonabant for prevention of cardiovascular events (CRESCENDO): A randomised, multicentre, placebo-controlled trial. Lancet, 376(9740), 517-523. https://doi. org/10.1016/S0140-6736(10)60935-X

Tsou, K., Brown, S., Sanudo-Pena, M. C., Mackie, K., \& Walker, J. M. (1998). Immunohistochemical distribution of cannabinoid CB1 receptors in the rat central nervous system. Neuroscience, 83(2), 393-411.

U'Prichard, D. C. (1980). Multiple CNS receptor interactions of ergot alkaloids: Affinity and intrinsic activity analysis in in vitro binding systems. Advances in Biochemical Psychopharmacology, 23, 103-115.

van Vliet, S. A., Vanwersch, R. A., Jongsma, M. J., Olivier, B., \& Philippens, I. H. (2008). Therapeutic effects of Delta9-THC and modafinil in a marmoset Parkinson model. European Neuropsychopharmacology, 18(5), 383-389. https://doi.org/10.1016/j.euroneuro.2007.11.003

Verty, A. N., Evetts, M. J., Crouch, G. J., McGregor, I. S., Stefanidis, A., \& Oldfield, B. J. (2011). The cannabinoid receptor agonist THC attenuates weight loss in a rodent model of activitybased anorexia. Neuropsychopharmacology, 36(7), 1349-1358. https://doi.org/10.1038/npp. 2011.19

Wacker, D., Wang, S., McCorvy, J. D., Betz, R. M., Venkatakrishnan, A. J., Levit, A., , . Roth, B. L. (2017). Crystal structure of an LSD-bound human serotonin receptor. Cell, 168(3), 377-389. e312. https://doi.org/10.1016/j.cell.2016.12.033

Weber, M., Goldman, B., \& Truniger, S. (2010). Tetrahydrocannabinol (THC) for cramps in amyotrophic lateral sclerosis: A randomised, double-blind crossover trial. Journal of Neurology, Neurosurgery \& Psychiatry, 81(10), 1135-1140. https://doi.org/10.1136/jnnp.2009.200642

Winkelman, M. (2014). Psychedelics as medicines for substance abuse rehabilitation: Evaluating treatments with LSD, peyote, ibogaine and ayahuasca. Current Drug Abuse Reviews, 7(2), $101-116$.

Xapelli, S., Agasse, F., Sarda-Arroyo, L., Bernardino, L., Santos, T., Ribeiro, F. F., . . Malva, J. O. (2013). Activation of type 1 cannabinoid receptor (CB1R) promotes neurogenesis in murine subventricular zone cell cultures. PLoS One, 8(5), e63529. https://doi.org/10.1371/journal.pone. 0063529

Yu, Y. Z., Liu, S., Wang, H. C., Shi, D. Y., Xu, Q., Zhou, X. W., .. Huang, P. T. (2016). A novel recombinant 6Abeta15-THc-C chimeric vaccine (rCV02) mitigates Alzheimer's disease-like pathology, cognitive decline and synaptic loss in aged 3 x Tg-AD mice. Scientific Reports, 6, 27175. https://doi.org/10.1038/srep27175

Zani, A., Braida, D., Capurro, V., \& Sala, M. (2007). Delta9-tetrahydrocannabinol (THC) and AM 404 protect against cerebral ischaemia in gerbils through a mechanism involving cannabinoid and opioid receptors. British Journal of Pharmacology, 152(8), 1301-1311. https://doi.org/10. 1038/sj.bjp.0707514

Zarate, C. A., Jr., Singh, J. B., Carlson, P. J., Brutsche, N. E., Ameli, R., Luckenbaugh, D. A., . . Manji, H. K. (2006). A randomized trial of an N-methyl-D-aspartate antagonist in treatmentresistant major depression. Archives of General Psychiatry, 63(8), 856-864. https://doi.org/10. 1001/archpsyc.63.8.856

Zettl, U. K., Rommer, P., Hipp, P., \& Patejdl, R. (2016). Evidence for the efficacy and effectiveness of THC-CBD oromucosal spray in symptom management of patients with spasticity due to 
multiple sclerosis. Therapeutic Advances in Neurological Disorders, 9(1), 9-30. https://doi.org/ $10.1177 / 1756285615612659$

Zuardi, A. W., Crippa, J. A., \& Hallak, J. E. (2010). Cannabis sativa: A planta que pode produzir efeitos indesejáveis e também tratá-los [Cannabis sativa: The plant that can induce unwanted effects and also treat them]. Revista Brasileira de Psiquiatria, 32(Suppl 1), S1-S2.

Zuardi, A. W., Crippa, J. A., Hallak, J. E., Bhattacharyya, S., Atakan, Z., Martin-Santos, R., ... Guimaraes, F. S. (2012). A critical review of the antipsychotic effects of cannabidiol: 30 years of a translational investigation. Current Pharmaceutical Design, 18(32), 5131-5140.

Zurier, R. B. (2003). Prospects for cannabinoids as anti-inflammatory agents. Journal of Cellular Biochemistry, 88(3), 462-466. https://doi.org/10.1002/jcb.10291 